\title{
Um estudo sobre a realidade da inclusão de pessoas com deficiência na educação superior no Paraná
}

\author{
Hernestina da Silva Fiaux Mendes* \\ Camen Célia Barradas Correia Bastos**
}

\section{Resumo}

Este estudo integra as discussōes apresentadas na dissertação de Mestrado em Educação, na qual analisou a inclusão dos estudantes com deficiência na Educação Superior, com ênfase na análise de questôes de acesso, permanência e aprendizagem, buscando compreender o processo de inclusão dos mesmos em instituiçóes de Educaçáo Superior do município de Umuarama, na regiáo Noroeste do Paraná. Para o estudo, foram entrevistados estudantes matriculados, concluintes e desistentes, no período de 2008 a 2014. Utilizaram-se os pressupostos de uma pesquisa qualitativa/quantitativa, descritiva, analítica por ser considerada adequada na compreensão da vida dos participantes em seu cotidiano universitário, buscando-se identificar, por meio da análise dos dados obtidos nas entrevistas, os eixos norteadores deste estudo. A base bibliográfica é de autores que discutem a educação das pessoas com deficiência e a inclusão educacional na Educação Superior. O estudo revela como unidades de significados 1 - as dificuldades e desafios encontrados pelas pessoas com deficiência na Educação Superior especialmente no que se refere ao processo de ensino e aprendizagem; $2-$ as situaçóes de preconceito e; 3 - aspectos da acessibilidade, bem como, a importância da participação da família na vida acadêmica, como elementos fundamentais para a permanência ou abandono desses estudantes nas IES.

Palavras-chave: Inclusão; Educação Superior; Deficiência.

\footnotetext{
* Professora Mestre em Educação, Núcleo Regional da Educação, Umuarama, Estado do Paraná, Brasil.
}

** Professora doutora da Universidade Estadual do Oeste do Paraná, Cascavel, Paraná, Brasil. 


\section{A study on disabled people inclusion reality in higher education in Paraná}

\section{Abstract}

This study integrates the discussions shown in the Master's thesis in Education, in which it was analyzed the disabled students inclusion in the Higher Education, emphasizing the access, staying and learning issues, seeking to understand the inclusion process of these students in Higher Education Institutions in Umuarama City, in Parana Northwest region. For study, enrolled students, concluding and dropout were interviewed, from 2008 to 2014. Analytical, descriptive, qualitative/quantitative research presuppositions were used to be considered appropriated in understanding the participants' life in their university routine, trying to identify, by analysis of data from interviews, the guidelines of this study. The bibliographic basis is of the authors who talk about disabled people education and the educational inclusion in Higher Education. The study shows as study meaning units the difficulties and challenges faced by disable people in Higher Education specially referring to the teaching and learning process, prejudiced situations and accessibility aspects, as well as, the importance of the family participation in academic life, like fundamental elements to the stay or dropout of these students in the Higher Education Institutions (HEI).

Keywords: Inclusion; Higher Education; Deficiency.

\section{Introdução}

A pesquisa realizada como base documentos norteadores da educação especial na construção de conhecimento da História da Educação principalmente de pessoas com deficiência. Optamos por conhecer um recorte do histórico da educação e propostas oficiais divulgadas pelo MEC (Ministério da Educação), suas possibilidades de atendimentos educacionais para as pessoas com deficiência. Para estudo bibliográfico, tomamos como referência teórica autores que discutem e estudam a educação de pessoas com necessidades educacionais especiais para a inclusão na Educação Superior.

A partir da configuração histórica sobre o tema construímos eixos referentes à educação especial, para chegarmos à proposta de educação inclusiva, objetivando compreender o processo educativo e sua relevância para a humanização da pessoa com deficiência ao longo de sua trajetória histórica. Como sabemos, essas pessoas apresentam um quadro histórico de exclusão educacional, sendo que muitas, durante um longo período, foram estigmatizadas e restringidas a práticas segregativas como sendo única possibilidade educativa. $\mathrm{O}$ processo de inclusão de pessoas com deficiência no ensino comum é algo recente e vêm sendo apresentado como assunto de grandes debates em discussóes educacionais, tanto em relação às políticas de atendimentos às necessidades, como no diálogo dos educadores em relação aos atendimentos às necessidades em sala de aula. Observamos que a inclusão dessas pessoas não demonstra muitos avanços. Mesmo com seus direitos garantidos legalmente, o percentual de matrículas é baixo, pois poucas pessoas ingressam na Educação Superior. 
A pesquisa focaliza a análise de questóes de acesso, permanência e aprendizagem, fazendo um recorte da inclusão na Educação Superior, entre 2008 e 2014. O interesse pelo tema surge da trajetória de experiência na área da educação especial e por ser um assunto desafiador. No decorrer desse percurso, o contato com as pessoas com deficiência nos possibilitou maior dedicação pessoal e profissional, conduzindo às buscas teóricas e práticas para suprir necessidades de compreensão implicadas no trabalho com a educação especial. Nos últimos anos, as políticas inclusivas preconizam não só o acesso e permanência, mas, sobretudo, um ensino que possibilite uma aprendizagem com qualidade.

Nas Instituições de Educação Superior (IES), públicas e privadas no Brasil e no Paraná, há exigência legal de implantação de núcleos de apoio e acompanhamento para dar atendimento às necessidades educacionais dos estudantes com deficiência e suporte aos professores em termos de apoio às adequaçóes curriculares, mas essa ação não tem adesão de todas as Instituições e também os núcleos de atendimento não têm sido eficientes em relação à demanda, conforme dados levantados neste estudo por meio das entrevistas realizadas com os estudantes com deficiência. Nas Universidades, as pesquisas apontam muitos fatores impeditivos em relação ao processo de inclusão.

\section{Discussão da temática educação inclusiva}

O movimento pela educação inclusiva ganha força no Brasil entre os anos de 1980 e, mais especificamente em 1990, traz possibilidade do acesso de pessoas com deficiência ao ensino comum, nessa esteira, a inclusão na Educação Superior no Brasil integra-se aos debates. Atualmente, discutem-se políticas de inclusão, ampliando o acesso as matrículas na Educação Superior, mas um dos grandes desafios têm sido as condiçóes de acessibilidades físicas, metodológicas e a garantia de um ensino de qualidade que assegure a permanência destas pessoas nas Instituiçóes.

Nessa trajetória da educação inclusiva, há que se considerar que uma universidade, na perspectiva inclusiva, não surge de um momento para outro, ela tende a se desenvolver ao longo de processos de mudanças, que visam à desconstrução de conceitos, preconceitos, eliminação de barreiras de toda a espécie e de concepçóes segregadoras e excludentes cristalizadas pela sociedade. Para Moreira (2004, p.36), "até 1990, as políticas referentes à educação especial estiveram voltadas para a garantia de atendimento, não necessariamente educacional, com tendência ao assistencialismo e à perspectiva terapêutica”. A partir de 1990, com a Declaração de Jontien, na Tailândia, começaram os avanços na busca de uma educação para todos, direcionando para o paradigma da inclusão.

Não podemos negar que, no Brasil, a partir da década de 1990, criou-se grande percentual de leis Federal, Estadual e Municipal, intencionando defender os direitos das pessoas com deficiência e a diversidade como um todo. A LDB 9.394/1996 preconiza em seus artigos, mudanças na escola ao garantir currículos, métodos, recursos educativos e organizaçóes diferenciadas para atender às especificidades e necessidades dos estudantes (BRASIL, 1996). 
Nesse sentido, a Política Estadual da Educação Especial na Perspectiva da Inclusão, afirma que o desafio da inclusão escolar é enfrentado como uma nova forma de repensar e reestruturar políticas e estratégias educativas, de maneira a criar oportunidades efetivas de acesso às crianças, jovens e adultos com necessidades educacionais especiais, mas, sobretudo, garantir condiçóes indispensáveis para manterem-se na escola e aprender (PARANÁ, 2009).

Também não se pode ignorar que muitas IES têm realizado açóes importantes para a efetivação do acesso do estudante com deficiência, que estão sendo oferecidas bancas especializadas, professor intérprete para surdos, ledores para cegos, provas ampliadas para pessoas com baixa visão e outros atendimentos especializados, para atender as pessoas com deficiência durante o processo seletivo. Consideramos que, quanto ao acesso, as universidades têm possibilitado os recursos necessários, porém a permanência não esta sendo garantidos nos ambientes universitários, muitos ingressam e não conseguem prosseguir por falta de condiçóes de acessibilidade.

Todas essas conquistas são decorrentes de lutas de pessoa com deficiência, família, movimentos sociais e comunitários, implantação de leis, decretos, resoluçôes, visando à sensibilização da sociedade com relação à inclusão. Porém, apesar de todos os esforços e políticas à favor da inclusão na Educação Superior, encontramos mazelas, dificuldades e atitudes preconceituosas que precisam ser superadas ao longo do processo de inclusão.

Nesta direção, Rodrigues (2011, p. 66) alerta que às Instituições de Educação Superior cabe promover debate sobre o tema e instrumentalizar, qualificar profissionais da educação para o exercício pleno da docência com vistas ao atendimento educacional de todos os sujeitos com ou sem deficiência. Isso implica trazer sempre à tona a questão sobre o papel e convicçóes do professor, em todas as modalidades de ensino. Segundo depoimentos dos participantes da pesquisa, os professores não se acham preparados para atender esse público. Assim percebermos que os cursos universitários não estão atentos a isso e a maioria das matrizes curriculares não ofertam disciplinas ligadas à educação especial.

Segundo a LDEBN (9394/96), no artigo 62, a formação de docente para atuar na educação básica far-se-a em nível superior, em curso de licenciatura de graduação plena, em universidades e institutos superiores de educação, admitida como formação mínima para exercício do magistério. Pois o movimento pela inclusão "está ligado à valorizaçấo de todas as pessoas, independente de suas diferenças individuais, inclusive àquelas com deficiências" (FERNANDES, 2007, p. 45).

Entretanto, apesar dos direitos garantidos legalmente, deparamo-nos no decorrer deste estudo, com números inexpressíveis de matrículas de pessoas com deficiência das IES, na regiáo do município de Umuarama. Os dados trazidos pelo censo escolar MEC/INEP 2009 revelam um acréscimo no percentual de alunos público-alvo da educaçáo especial, matriculados nas classes comuns do ensino regular. Podemos perceber que em 2002, esse número era de 28\%, enquanto em 2009 passou para 56\%. Na Educação Superior eles estão chegando, embora em número reduzido comparado à Educação Básica. 
É importante ressaltar que as Instituições de Educação Superior, para garantir aos estudantes o direito à educação e aderir ao processo de inclusão, necessitam mobilizar-se para eliminar barreiras físicas, programáticas e atitudinais e possibilitar o acesso aos serviços e comunicaçóes. Portanto, o interesse por este assunto visa desvendar alguns aspectos em relação a esta temática. O nosso objetivo principal é compreender a trajetória acadêmica dos estudantes com deficiência na Educação Superior das IES da regiáo de Umuarama, identificando suas dificuldades e necessidades no percurso da graduação, considerando questóes relativas ao acesso, permanência e aprendizagem por meio de pesquisa de campo, utilizando, como instrumento para a coleta de dados entrevistas. O estudo foi desenvolvido com a intenção de entender o universo destas pessoas na Educação Superior e se os mesmos estão conseguindo apropriar-se dos conhecimentos científicos. Nos últimos anos, há um aumento de estudantes especiais procurando a Educação Superior? Os que chegam à Educação Superior estâo permanecendo? E os que permaneceram estão obtendo níveis satisfatórios de aprendizagem?

Para iniciarmos os trabalhos, foram realizados levantamentos das matrículas dos estudantes com deficiência na Educação Superior, tomando como universo as instituiçóes UEM, UNIESP e ALFA, do município de Umuarama, fazendo um recorte das matrículas efetivadas nos respectivos anos de 2008 a 2014. Para análise, foram levantados números de estudantes concluintes, matriculados e desistentes.

As informaçôes colhidas foram de professores, pessoas do setor administrativo das instituiçóes. Nesse período de levantamento de informaçóes, alguns fatores nos chamaram a atenção em relação à omissão de informaçôes no momento da matrícula, pois a maioria das pessoas com deficiência não se autodeclaram como deficientes e algumas Instituiçôes de Educação Superior não especificam nos registros das matrículas se o estudante apresenta algum tipo de deficiência. Durante o percurso investigativo, deparamo-nos com Instituição que se recusou a participar da pesquisa.

Os dados nos mostram que os números de matrículas de estudantes com deficiência são insatisfatórios, considerando a demanda de estudantes considerados "normais", e o maior fluxo de matrículas de estudantes com deficiência está nas IES privadas, ou seja, poucos estudantes procuram as IES públicas.

\section{Percurso metodológico da pesquisa}

Para o desenvolvimento da pesquisa, utilizamos pressupostos da modalidade de pesquisa qualitativa/quantitativa, analítica e descritiva por considerarmos adequados para compreensáo do objeto de estudo. A investigaçáo foi realizada em três IES, sendo duas privadas e uma pública. Fizeram parte da pesquisa onze estudantes com deficiência na faixa etária entre vinte e quarenta e sete anos. Sendo seis do sexo masculino e cinco do sexo feminino. Em relação à matrícula, dez estudantes de IES privadas e apenas um de Instituiçáo Pública. De acordo com Rossetto (2009) nas instituiçóes do ensino privado, encontra-se um maior número de matrículas de estudantes com deficiência. 
Participaram da pesquisa dois estudantes cegos; dois estudantes com deficiência física neuromotora; três estudantes com deficiência física adquirida. Desses, dois foram vítimas de acidente e outro desenvolveu uma doença, cujo nome não científico é "ossos de vidro"; dois utilizam cadeiras de rodas e o outro se locomove com auxílio de próteses nas duas pernas. Entrevistamos também uma estudante surda e duas estudantes com deficiência auditiva, que apresentam perda significativa da audição, utilizando-se de prótese para preservar alguns resíduos auditivos.

Não houve critérios para a seleção dos estudantes com deficiência, por termos um número reduzido de matrículas deles nas IES. Foram entrevistados todos aqueles que conseguimos localizar e que aceitaram participar da pesquisa, relatando suas histórias de vida acadêmica.

O levantamento de informaçôes foi um processo difícil. Muitos estudantes não informam no formulário de matrícula a deficiência. Alguns declaram que possuem deficiência, mas a maioria parece não ter clareza quanto às características das deficiências. Encontramos muitos casos de estudantes que se colocam como deficientes visuais por usarem óculos ou deficientes físicos, por serem canhotos, como nos mostram as contradiçóes expostas no quadro abaixo.

Em uma das Instituições pesquisadas, houve um equívoco em relação ao número de pessoas com deficiência. No primeiro contato com a IES, informaram-nos que havia, na unidade de Umuarama, 54 estudantes com deficiência, sendo 46 com deficiência visual e os outros distribuídos nas outras áreas das deficiências como segue o quadro abaixo.

Quadro 1 - No de estudantes matriculados em uma IES, cujos dados foram alterados posteriormente. Fonte: dados colhidos pelas autoras da pesquisa.

\begin{tabular}{|l|c|c|c|c|c|}
\hline Matrículas & $\begin{array}{c}\text { No de Def. } \\
\text { Física }\end{array}$ & $\begin{array}{c}\text { No de Def. } \\
\text { Auditiva e } \\
\text { Surdez }\end{array}$ & $\begin{array}{c}\text { No de Def. } \\
\text { Visual }\end{array}$ & $\begin{array}{c}\text { No de Def. } \\
\text { Intelectual }\end{array}$ & $\begin{array}{c}\text { Total de } \\
\text { Estudantes com } \\
\text { Deficiência }\end{array}$ \\
\hline 2008 & 00 & 01 & 11 & 01 & 12 \\
\hline 2009 & 01 & 01 & 11 & 01 & 14 \\
\hline 2010 & 01 & 00 & 06 & 00 & 07 \\
\hline 2011 & 00 & 00 & 04 & 00 & 04 \\
\hline 2012 & 00 & 02 & 10 & 00 & 12 \\
\hline 2013 & 01 & 00 & 04 & 00 & 05 \\
\hline 2014 & 00 & 00 & 00 & 00 & 00 \\
\hline
\end{tabular}

Ao contatarmos novamente a Universidade para levantamento dos endereços dos estudantes para marcarmos as entrevistas, informaram-nos que náo havia estudantes com deficiência no campus. Disseram que houve um engano por parte dos estudantes em declararem-se como deficientes visuais por fazerem uso de óculos ou físico por serem canhotos. Algumas pessoas com diagnóstico de dislexia e TDAH (transtorno do déficit de atenção/hiperatividade) foram consideradas com deficiência 
na ficha de matrícula. Com relação aos dados, o número de estudantes com deficiência baixou para uma estudante com deficiência visual que havia concluído o curso em 2008. Essa discrepância revela desconhecimento do assunto pelos profissionais das IES e pelos próprios estudantes.

A partir do levantamento do número de estudantes matriculados na Educação Superior, iniciamos visitas às IES para levantamento dos nomes e contatos dos estudantes a fim de iniciarmos as entrevistas.

Como instrumentos de coleta de dados, utilizamos roteiros de entrevista semiestruturada com questôes abertas, visando à garantia de obtermos mais detalhes sobre as percepções dos participantes em relação a nossa investigação. As entrevistas possibilitaram maior interação entre entrevistados e pesquisadoras. Como afirma Gil, este instrumento "tem vantagem na obtenção de dados referentes aos mais diversos aspectos da vida social (GIL, 2007, p. 117-118, apud, LIMA, 2011, p. 77)”. Ainda, conforme Trivinôs (1996), a utilização da técnica de pesquisa com entrevista semiestruturada tende a valorizar a presença do pesquisador e ao mesmo tempo oportuniza ao sujeito pesquisado a liberdade e a espontaneidade necessárias, favorecendo o enriquecimento da atividade de investigaçáo. Segundo Pereira, "A técnica de entrevista é o procedimento mais usual no trabalho de campo, pois através desta, o pesquisador busca o acesso ao significado da fala dos atores sociais" (2007, p. 108).

\section{Histórias de vida acadêmica dos participantes na educação superior}

Passaremos a relatar as histórias de vida acadêmica dos sujeitos da pesquisa. Utilizamos nomes fictícios.

Quadro 2 - caracterizaçấo dos sujeitos da pesquisa. Fonte: dados colhidos pelas autoras da pesquisa.

\begin{tabular}{|c|c|c|c|c|}
\hline NOME & SITUAÇÃO & IDADE & DEFICIÊNCIA & CURSO \\
\hline Valter & $\begin{array}{c}\text { Cursando - } \\
1^{\circ} \text { ano }\end{array}$ & 27 & Física & $\begin{array}{l}\text { Sistema para } \\
\text { Internet }\end{array}$ \\
\hline Geraldo & $\begin{array}{c}\text { Desistente - } \\
1^{\circ} \text { ano }\end{array}$ & 29 & Física & Processos Gerenciais \\
\hline Pedro & $\begin{array}{c}\text { Cursando - } \\
2^{\circ} \text { ano }\end{array}$ & 40 & Física & Ciências Biológicas \\
\hline Roberto & $\begin{array}{c}\text { Formado - } \\
2011\end{array}$ & 26 & $\begin{array}{c}\text { Física } \\
\text { Neuromotora }\end{array}$ & Direito \\
\hline David & $\begin{array}{c}\text { Formado - } \\
2013\end{array}$ & 31 & $\begin{array}{c}\text { Física } \\
\text { Neuromotora }\end{array}$ & $\begin{array}{l}\text { Sistema para } \\
\text { Internet }\end{array}$ \\
\hline Antonio & $\begin{array}{c}\text { Desistente - } \\
4^{\circ} \text { ano }\end{array}$ & 32 & Cego & Psicologia \\
\hline Emanuele & $\begin{array}{c}\text { Formada }- \\
2008\end{array}$ & 47 & Cega & $\begin{array}{c}\text { Tecnologia de } \\
\text { Alimentos }\end{array}$ \\
\hline
\end{tabular}




\begin{tabular}{|l|c|c|c|c|}
\hline Talita & $\begin{array}{c}\text { Cursando }- \\
3^{\circ} \text { ano }\end{array}$ & 20 & Auditiva & Letras \\
\hline Marisa & $\begin{array}{c}\text { Cursando }- \\
4^{\circ} \text { ano }\end{array}$ & 21 & Auditiva & Fonoaudiologia \\
\hline Olga & $\begin{array}{c}\text { Formada - } \\
2013\end{array}$ & 22 & Surda & Estética Cosmética \\
\hline Carolina & $\begin{array}{c}\text { Desistente }- \\
2^{\circ} \text { ano }\end{array}$ & $\begin{array}{c}\text { Não quis ser } \\
\text { entrevistada }\end{array}$ & Intelectual & Ciências Biológicas \\
\hline
\end{tabular}

Deficiência Intelectual - Carolina apresenta hidrocefalia, ingressou na IES em 2011 e em 2012 desistiu do curso. Ela não aceitou ser entrevistada.

Deficiência Visual - Emanuele, ao iniciar a graduação, já possuía uma doença na visão que agravou-se com o tempo, perdendo a visão. No início, foi difícil para ela e família, de quem sempre teve apoio, mas quando mais necessitou desse auxílio, teve de enfrentar suas barreiras praticamente só, pois os pais entraram em depressão e ela precisou ser forte. Na IES, não teve grandes problemas, tinha assistência de um programa de apoio a pessoas com deficiência. Em sala, fazia uso de notebook e os professores encaminhavam todo seu material via e-mail. Tinha mais dificuldades em relação à acessibilidade física e em algumas atividades no laboratório das aulas práticas.

Antônio tinha o apoio da mãe para pegar os materiais das aulas, conseguia acompanhar o curso sem muitas dificuldades. Mas, a partir do $4^{\circ}$ ano, sua mãe não pode mais acompanhá-lo, nas atividades que necessitava de auxílio, passou por muitas dificuldades e desistiu do curso. Professores diziam que ele era muito inteligente e daria conta de aprender.

Surdez - Olga terminou o curso superior em estética, no qual contou com o professor intérprete. Mas, quando precisou de mais de um intérprete para as aulas práticas nos laboratórios, a IES não quis contratar, alegando que não haver necessidade, porque a estudante falava bem e uma nova contratação oneraria a instituição.

Olga relatou que já nasceu surda e um determinado professor exigia que ela the dirigisse o olhar, irritando-se quando ela olhava para a tradução da intérprete.

Deficiência Auditiva - Marisa relatou não ter encontrado dificuldades, porque ouve um pouco e faz leitura labial. Disse que a maioria dos professores não falava de frente para ela e, se tivessem esse cuidado, facilitaria sua participação nas aulas. Conta com o auxílio da mãe que ingressou na IES para ajudá-la em sala e nos trabalhos. Como relatamos, a participação da família na Educação Superior tem sido uma prática.

A estudante Talita cursava o terceiro ano de graduação, apresentava perda auditiva acentuada, usa prótese, faz leitura labial e ouve pouco. Durante os anos na IES, passou por muitas dificuldades. Os professores não entendiam que ela precisava olhar no rosto deles para compreender a explicação. Sofreu preconceito por parte dos colegas e professores quando apresentava trabalhos, a sala a chamava de "surdinha". 
Quando o professor falava algo que ela não entendia, a amiga escrevia em bilhete e passava a ela.

Deficiência Física - os estudantes com deficiência física, Valter e Geraldo, apresentam comprometimentos nos membros inferiores e usam cadeiras de rodas. Não tiveram dificuldades de adequaçóes e recursos pedagógicos por terem os membros superiores preservados, inicialmente tiveram dificuldades de acessibilidade física. Mas as IES resolveu esse problema. Valter disse que frequentemente os professores são rápidos nas explicaçóes e ele não consegue acompanhar a aula: prestar atenção e anotar ao mesmo tempo.

Deficiência Física Neuromotora - Roberto apresenta comprometimento na coordenação motora fina e ampla das mãos, não consegue escrever a caneta, faz uso do computador com algumas adaptaçóes, comunica-se oralmente com alguma dificuldade de articulação e utiliza cadeira de rodas. Ao inscrever-se para o vestibular, declarou-se deficiente físico. Dias antes da seleção, a IES convidou família para uma reunião com uma "comissáo julgadora" . A equipe questionou seus pais se o estudante teria condições de acompanhar o curso. Queria saber se ele solicitaria um profissional de apoio, se necessário, a IES não tinha profissional especializado para oferecer. A família respondeu que não iria exigir nada da Instituição. Roberto relatou que a mãe se formou no mesmo curso para assessorá-lo durante a graduação. Durante os dois primeiros anos, a mãe fez todo acompanhamento, depois os amigos da sala se prontificaram a ajudá-lo. Roberto disse que os amigos, os professores e a família foram importantes para que concluísse a graduação.

David também apresenta deficiência física neuromotora com comprometimentos nos membros inferiores, superiores e na fala. Em sala de aula, comunicava-se com o notebook, tinha dificuldades para acompanhar as atividades devido à lentidão que apresenta para digitar. Os movimentos descoordenados com as mãos dificultam a escrita. Segundo a mãe, às vezes, o estudante chegava nervoso em casa dizendo que os professores não tinham paciência com ele. A mãe precisava ligar na IES, conversar com o coordenador do curso e tentar resolver os conflitos entre os professores e David. Durante a graduação, o estudante conversava e pedia auxílio para uma Professora de Apoio à Comunicação Alternativa que o acompanhou no Ensino Médio. Essa professora, por várias vezes, foi procurada pelos professores da IES para ajudá-los nas dificuldades referentes ao desempenho do estudante. David, depois de muito sacrifício e força de vontade, concluiu a graduação.

\section{Considerações sobre os relatos de vida das pessoas com deficiência na Educação Superior}

Vale ressaltar que, apesar de respaldo legal, existem muitos desafios a serem enfrentados para a concretizaçấo da inclusão nas IES. Entendemos que as leis são necessárias para nortear os trabalhos pedagógicos, mas não podemos considerá-las suficientes para garantir aos estudantes a graduação. 
A análise dos dados revela que a permanência desses estudantes na Educação Superior ocorre em meio a muitas dificuldades, como falta de materiais adequados e preconceito. Açôes de responsabilidade das IES ficaram a cargo das famílias, que assumem papel relevante para que eles superem dificuldades impostas pela própria deficiência. A compreensão e estímulo de professores e de amigos são condiçóes que também os auxiliam na permanência e na conclusão do curso.

Com relação ao desempenho nas atividades acadêmicas, o ritmo dos estudantes não é respeitado. Os conteúdos não são disponibilizados via e-mail, que seria uma medida simples para facilitar o acesso ao conhecimento. A Lei N. ${ }^{\circ} 10.098$, criada em 19 e dezembro de 2000 , em seu capítulo I, art. $1^{\circ}$, institui normas gerais e critérios básicos para a promoção da acessibilidade das pessoas com deficiência ou com mobilidade reduzida, mediante a eliminação de barreiras e de obstáculos nas vias e espaços públicos, no mobiliário urbano, na construção e reforma de edifícios e nos meios de transporte e de comunicação; e, em seu art. $2^{\circ}$, faz algumas definiçóes, entre elas a acessibilidade, que se refere à possibilidade e condição de alcance para utilização, com autonomia e segurança, (Brasil, 2000), mas na prática infelizmente os direitos náo são respeitados, muitos estudantes precisam cobrar os recursos de acessibilidade via judicial.

Em relação aos estudantes surdos e com deficiência auditiva, vemos que suas condiçóes nas Universidades poderiam ser diferentes se fossem levadas em consideração suas diferenças linguísticas e suas necessidades específicas de aprendizagem. Muitas vezes, a desinformação nas Universidades causam situações de desconforto entre professores e estudantes, impossibilitando a aprendizagem.

No caso do deficiente auditivo, passando por dificuldades, deveriam ser resolvidas no início da graduação com medidas simples como falar de frente e compassadamente para que o estudante possa compreender as explicaçôes por leitura labial, também não são disponibilizados microfones nos laboratórios e, quando disponibilizados nos eventos, a qualidade do som não atende as suas necessidades.

Apesar de 12 anos de reconhecimento da LIBRAS como a primeira língua da pessoa surda, em uma sociedade tomada pelo discurso inclusivo, ainda permanecem práticas de intolerâncias às diferenças.

$\mathrm{O}$ reconhecimento do direito em comunicar-se por língua de sinais, garantido por meio do Decreto no 5.626/05, que regulamenta a Lei $n^{\circ} 10.436 / 2002$, dispóe sobre a inclusão de Libras como disciplina curricular e a formação e certificação de professor, instrutor e tradutor/intérprete de Libras. Foi reconhecido também o ensino da Língua Portuguesa como segunda língua para alunos surdos e propóe-se a organização da educação bilíngue para as pessoas surdas no ensino regular (Política Nacional da Educação Especial na Perspectiva da Educação Inclusiva 2008, p. 10). Sabemos que "a educação bilíngüe para os surdos impóe aos educadores um novo olhar não apenas sobre a situação lingüística em questão, mas, sobretudo, em relação às concepçôes axiológicas envolvidas nessa prática” (FERNANDES, 2008, p. 02). 
No entanto, é mais fácil encaminhar os estudantes com deficiência para um profissional especializado que buscar alternativas de atendimentos. Quando o estudante tem intérprete, transfere-se a responsabilidade de aprendizagem para ele. Segundo a orientação da Instrução 003/2012, que estabelece as normas para a atuação do tradutor e intérprete de Libras/Língua Portuguesa-TILS, esse profissional bilíngue tem a função de oferecer suporte pedagógico à escolarização de alunos surdos matriculados na Educação Básica, da rede regular de ensino, por meio da mediaçáo linguística entre aluno(s) surdo(s) e demais membros da comunidade escolar, de modo a assegurar o desenvolvimento da proposta de educação bilíngue (Libras/Língua Portuguesa) e deixando evidente a responsabilidade pela aprendizagem do estudante surdo para os professores das disciplinas.

Outras situaçóes enfrentadas por estudantes surdos é a falta de compreensão de alguns professores que duvidam da limitação. Por alguns se comunicarem oralmente, são obrigados a repetir, por diversas vezes, que, apesar de terem a linguagem oral, não ouvem. Alguns profissionais julgam que, se podem falar, são capazes de compreender com precisão e realizar leitura em língua portuguesa com eficiência. Vale ressaltar que são processos distintos, um é conseguir reproduzir a fala oralmente; outro é realizar a leitura labial do interlocutor e um terceiro é compreender a modalidade escrita da língua portuguesa.

Conforme Fernandes (2008, p. 03), estamos diante e de uma pseudo-inclusão que torna invisível a situação bilíngue dos surdos e produz diferenças de cidadania na sociedade, sinalizadas pelo fracasso escolar dos estudantes surdos na educação básica, revelado por altíssimos índices de repetência e evasão, pela quase inexistência de estudantes surdos que chegam a IES e em postos de trabalho.

Os resultados da nossa pesquisa confirmam que poucos estudantes surdos estão procurando a Educação Superior. Entre 2008 e 2014, encontramos uma matrícula e, segundo relato da estudante durante a graduação, por várias vezes, sentiu desejo em abandonar o curso, em virtude das dificuldades encontradas. Persistiu até o final por determinação pessoal em superar os obstáculos, por almejar uma formação acadêmica e ter uma atividade profissional.

Esses dados reafirmam que o tipo de encaminhamento metodológico adotado pelos professores assim como o relacionamento em sala de aula nas IES podem ser um dos principais condicionantes que colocam os estudantes surdos em desvantagem em seu processo de aprendizagem.

Quanto às pessoas com deficiência visual e cegueira, ressaltamos que é preciso considerar um conjunto de fatores que incidem sobre o desenvolvimento: a aprendizagem, a personalidade, o desempenho de tarefas corriqueiras. Pressupondo também a modificação de recursos pedagógicos, estratégias de aprendizagem e procedimentos para que ocorra o acesso ao conhecimento, bem como modificaçóes dos instrumentos de avaliação, adequados às condiçôes visuais desses educandos.

Um dos estudantes cego entrevistado não conseguiu prosseguir os estudos no $4^{\circ}$ ano de graduação por encontrar dificuldades em relação à disponibilização dos 
conteúdos via e-mail ou digitalizados, sendo uma ação simples que não exige conhecimentos técnicos específicos da área da deficiência. Diante do que rege o MEC/SEESP (2002), o compromisso com a formação do cidadáo com deficiência visual exige uma prática educacional voltada à compreensão da realidade social, dos direitos e das responsabilidades [...]. Além do acesso, é preciso oferecer condiçóes de aprendizagem a esses estudantes.

Não estamos dizendo que as Universidades tenham em criar um currículo específico que atenda aos estudantes com deficiência visual, pois, segundo o MEC/ SEESP (2002), "é preciso uma organização escolar que incorpore em seus objetivos e conteúdos básicos, o conhecimentos sobre a cegueira e o cego", ou seja, saber os recursos necessários que o estudante cego ou com baixa visão necessitam para aprendizagem, como, filmes auto descritivos, calculadoras para cegos, soroban, computadores com ledores, tele lupas, mapas em relevo, maquetes, disponibilização de materiais digitalizados ou via e-mail.

Como diz Sierra et al (2012), para ensinar pessoas com deficiência visual, cegas ou com baixa visão [...] antes de tudo é compreender como se dá a aquisição de conhecimento por eles, compreender quais fatores influenciam no aprendizado. $\mathrm{O}$ modo como o professor se coloca em relação ao estudante com deficiência pode fazer uma grande diferença em relação à dinâmica de sala, podendo levar estudantes e professores a ampliarem relaçóes concretas de interaçáo que contribuam para o processo de aprendizagem.

Considerando o que rege o artigo 24 da ONU, o direito da pessoa com deficiência à educação reforça a ideia de que "[...] para efetivar esse direito sem discriminação e com base na igualdade de oportunidades, os estados partes asseguraráo sistema educacional inclusivo em todos os níveis, bem como o aprendizado ao longo de toda a vida (ONU, 2006)". Esse princípio fundamenta a construção de um novo marco legal, político e pedagógico da educação especial, impulsionando os processos de elaboração e desenvolvimento de propostas pedagógicas que asseguraram condiçôes de acesso e participação de todos os estudantes no ensino comum.

Ressaltamos que as discussōes nessa área não se esgotam nesta pesquisa, uma vez que se torna pertinente ampliarmos nossos olhares à inclusão desses sujeitos na Educaçáo Superior, pois náo podemos de forma alguma repudiar ou menosprezar a inclusão deles neste nível de ensino, porque se assim o fizermos, estaremos negando um direito constitucional.

\section{Referências}

BRASIL. Política Nacional de Educação Especial na Perspectiva da Educação Inclusiva. MEC/SEESP. 2008.

Senado Federal. Lei de Diretrizes e Bases da Educaçáo Nacional: no 9394/96. Brasília: 1996. Disponível em: <http://portal.mec.gov.br/arquivos/pdf/ldb.pdf>. Acesso em: 17 abr. 2013.

Lei no 10.098, de 19 de dezembro de 2000. Disponível em: <http://www.planalto.gov.br/ccivil_03/ leis/110098.htm>. Acesso em: fev. 2015.

Lei 10.436 de 24.04.02 dispóe sobre a língua brasileira de sinais - LIBRAS, regulamentada pelo Decreto 5.626 de 22.12.05. Brasília, 2002. 
Ministério da Educação. Secretaria de Educação Especial. Programa Nacional de Apoio à Educaçáo de Deficientes visuais. Formaçáo de Professor. Brasília: MEC/SEESP, 2002.

Ministério da Educação. Portaria no 3.284 de 7 de novembro de 2003. Dispóe sobre requisitos de acessibiliade de pessoas portadoras de deficiências, para instruir os processos de autorização e de reconhecimento de cursos e de credenciamento de Instituiçóes. Brasília, 2003.

Decreto $\mathbf{n}^{\mathbf{0}}$ 5.296, de 02 de dezembro de 2004. Regulamenta as Leis nos 10.048, de 8 de novembro de 2000, que dá prioridade de atendimento às pessoas que especifica, e 10.098, de 19 de dezembro de 2000, que e estabelece normas gerais e critérios básicos para a promoção da acessibilidade das pessoas portadoras de deficiência ou com mobilidade reduzida, e dá outras providências. Brasília, DF, 2004.

Convençấo sobre o direito das pessoas com deficiência - Resoluçáo A/61/611 de 6 de dezembro de 2006. Brasília, 2006.

Instituto Nacional de Estudos e Pesquisas Educacionais Anísio Teixeira. Censo da Educação Superior 2009. Disponível em: <www.mec.gov.br-seesp>. Acesso em: 15 mar. 2014

FERNANDES, S. Fundamentos para Educação Especial. Curitiba: IBPEX, 2007, p. 45.

Letramentos na educaçáo bilíngue para surdos: caminhos para a prática pedagógica, Universidade Federal do Paraná - UFPR. Curitiba, 2008, p. 02-03.

LIMA, D. M. M. P. O professor universitário frente às estratégias de identificação e atendimento ao aluno com altas habilidades/superdotaçáo. Dissertação (mestrado em educação) - Universidade Federal do Paraná. Curitiba, 2011, p. 77.

MOREIRA, L. C. Universidade e estudantes com necessidades educacionais especiais: das açóes institucionais às práticas pedagógicas. São Paulo: USP, 2004. Tese (Doutorado em Educação). Faculdade de Educação da Universidade de Sáo Paulo, 2004, p. 36

PEREIRA, M. M. Inclusáo e universidade: analise de trajetórias acadêmicas na universidade estadual do rio grande do Sul, Porto Alegre - RS. UFRGS, 2007. Tese de (Mestrado em Educaçáo). Programa de pós-graduação em Educação da Universidade Federal do Rio Grande do Sul, 2007, p. 108.

UNESCO. Coordenadoria Nacional para a Integraçáo da Pessoa Portadora de Deficiência (CORDE). Declaraçáo de Salamanca: princípios, política e prática para as necessidades educativas especiais. Brasília, 1994.

Declaraçáo mundial sobre educaçáo para todos. Plano de ação para satisfazer as necessidades básicas de aprendizagem. Tailândia, 1990

PARANÁ. Secretaria de estado da Educação Superintendência da Educação. Instruçáo no 003/2012 - SEED/ SUED. Tradutor e intérprete de Língua Brasileira de Sinais-Libras/Língua Portuguesa- TILS nos Estabelecimentos de Ensino da Rede Pública Estadual. Curitiba, 2012.

Secretaria de Estado da Educação. Departamento de Educação Especial e Inclusão Educacional. Política Estadual de Educaçáo Especial na Perspectiva da Inclusáo. Curitiba, 2009. Disponível em: <http://www. nre.seed.pr.gov.br/londrina/arquivos/File/1politicasemanapedfev2010.pdf>. Acesso em: abr. 2014.

RODRIGUES, M. O Desafio da Inclusão Escolar das Pessoas com Deficiência: Reflexôes da Educação Superior Básica. In: SOUZA, A. M. L.; RODRIGUES, M. (Orgs.). Educaçáo Superior: outros olhares. 1 ed. Curitiba, PR: CRV, 2011, p. 66.

ROSSETTO, E. Sujeitos com Deficiência no Ensino Superior: vozes e significados, (tese de Doutorado) Universidade Federal do Rio Grande do Sul. Porto Alegre, 2009.

SIERRA, M. A. B. et al. O Atendimento Educacional Especializado: para alunos com deficiência visual: cegueira e baixa visão. In: MORI, N. N. R.; JACOBSEN, C. C. (Orgs.). Atendimento Educacional Especializado no Contexto da Educaçáo Básica. Maringá: Eduem, 2012.

TRIVIÑOS, A. N. S. Introduçáo à pesquisa em ciências sociais: a pesquisa qualitativa em educação. São Paulo: Atlas, 1996. 
Hernestina da Silva Fiaux Mendes - Camen Célia Barradas Correia Bastos

\section{Correspondência}

Hernestina da Silva Fiaux Mendes - Núcleo Regional da Educaçăo de Umuarama. Av. Castelo Branco, n. 3328 - Zona VI - CEP: 87503-200 - Umuarama, Paraná - Brasil.

E-mail: tinafiaux@hotmail.com - carmencbcb@yahoo.com.br

Recebido em 11 de março de 2015

Aprovado em 27 de julho de 2015 